\title{
Serum Tenascin-C as a Novel Predictor for Risk of Coronary Artery Lesion and Resistance to Intravenous Immunoglobulin in Kawasaki Disease
}

- A Multicenter Retrospective Study -

Yoshiaki Okuma, MD; Kenji Suda, MD, PhD; Hideyuki Nakaoka, MD;

Yasuhiro Katsube, MD, PhD; Yoshihide Mitani, MD, PhD; Yukako Yoshikane, MD, PhD;

Fukiko Ichida, MD, PhD; Takeji Matsushita, MD; Hiroyuki Shichino, MD;

Isao Shiraishi, $\mathrm{MD}, \mathrm{PhD}$; Jun Abe, $\mathrm{MD}, \mathrm{PhD}$; Michiaki Hiroe, $\mathrm{MD}, \mathrm{PhD}$;

Toshimichi Yoshida, MD, PhD; Kyoko Imanaka-Yoshida, MD, PhD

\begin{abstract}
Background: Tenascin-C (TN-C) is an extracellular matrix glycoprotein that is heavily upregulated at sites of inflammation. We conducted a retrospective study to assess the utility of TN-C as a novel biomarker to predict the risk of developing coronary artery lesions (CAL) and resistance to intravenous immunoglobulin (IVIG) in patients with Kawasaki disease (KD).

Methods and Results: We collected blood samples of $111 \mathrm{KD}$ patients (IVIG-responder: 89, IVIG-resistant: 22; CAL: 8 ) and 23 healthy controls, and measured the serum levels of TN-C. TN-C levels on admission were significantly higher in patients than in healthy controls and in patients during convalescence after IVIG administration (69.6 vs. 20.4 vs. $39.7 \mathrm{ng} / \mathrm{ml}$, respectively; $\mathrm{P}<0.001)$, and correlated positively with $C$-reactive protein $(P<0.001)$, neutrophil (percentage; $P=0.005)$, and ALT $(P<0.001)$, and negatively with platelet count $(P=0.023)$ and sodium level $(P=0.025)$. On admission, TN-C levels in patients who later developed CAL were significantly higher than in those without CAL $(P=0.010)$, and significantly higher in IVIG-resistant subjects than in IVIG-responders $(P=0.003)$. The accuracy of TN-C testing for the prediction of IVIG resistance was comparable to that of the Kobayashi score.
\end{abstract}

Conclusions: Serum TN-C could be a biomarker for predicting the risk of developing CAL and IVIG resistance during the acute phase of KD. (Circ $J$ 2016; 80: 2376-2381)

Key Words: Biomarkers; Coronary artery lesions; Intravenous immunoglobulin (IVIG) resistance; Kawasaki disease; Tenascin-C

$\mathbf{K}$ awasaki disease (KD) is an acute febrile illness of childhood characterized by systemic vasculitis of unknown origin. ${ }^{1}$ Coronary artery lesions (CAL) constitute the most critical complication of KD and can lead to myocardial infarction (MI) and death or chronic distress in adulthood. High-dose intravenous immunoglobulin (IVIG) therapy can subdue the inflammation in $\mathrm{KD}$ and reduce the occurrence of CAL. ${ }^{2-4}$ However, approximately $20 \%$ of KD patients show resistance to a single course of IVIG therapy. ${ }^{5}$ Many studies have shown that these IVIG-resistant patients have a greater risk of CAL. ${ }^{6-8}$ Currently, several scoring systems that combine multiple clinical parameters are used to

Received June 9, 2016; revised manuscript received September 7, 2016; accepted September 25, 2016; released online October 15, 2016 Time for primary review: 48 days

Department of Pediatrics (Y.O., T.M., H.S.), Department of Cardiology (M.H.), National Center for Global Health and Medicine, Tokyo; Course of Advanced and Specialized Medicine, Juntendo University Graduate School of Medicine, Tokyo (Y.O., H.S.); Department of Pediatrics and Child Health, Kurume University School of Medicine, Kurume (K.S.); Department of Pediatrics, Faculty of Medicine, University of Toyama, Toyama (H.N., F.I.); Department of Pediatrics, Nippon Medical School, Tokyo (Y.K.); Department of Pediatrics (Y.M.), Department of Pathology and Matrix Biology (T.Y., K.I.-Y.), Mie University Graduate School of Medicine, Tsu; Department of Pediatrics, Faculty of Medicine, Fukuoka University, Fukuoka (Y.Y.); Department of Pediatric Cardiology, National Cerebral and Cardiovascular Center, Osaka (I.S.); Department of Allergy and Immunology, National Research Institute for Child Health and Development, Tokyo (J.A.); and Mie University Research Center for Matrix Biology, Tsu (T.Y., K.I.-Y.), Japan

Mailing address: Yoshiaki Okuma, MD, Department of Pediatrics, National Center for Global Health and Medicine, 1-21-1 Toyama, Shinjuku-ku, Tokyo 162-8655, Japan. E-mail: yokuma@hosp.ncgm.go.jp

ISSN-1346-9843 doi:10.1253/circj.CJ-16-0563

All rights are reserved to the Japanese Circulation Society. For permissions, please e-mail: cj@j-circ.or.jp 


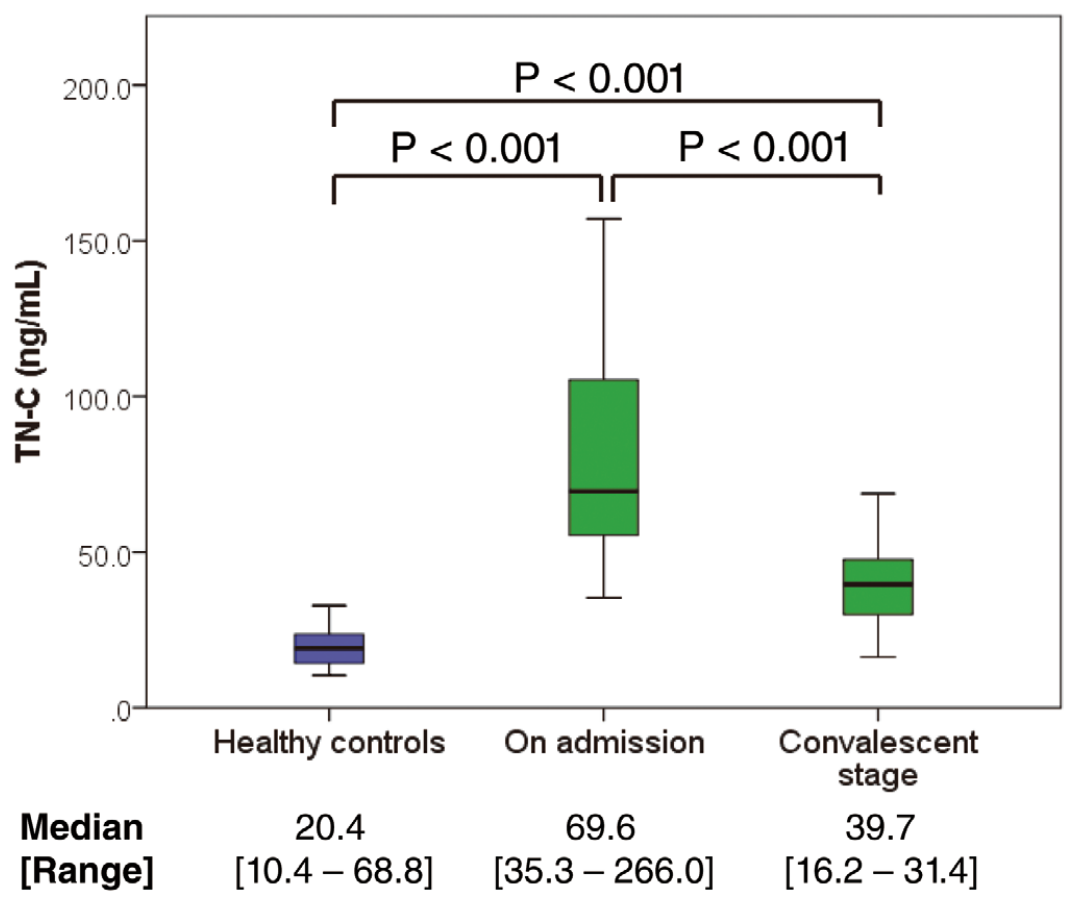

Figure 1. Serial changes in tenascin$\mathrm{C}(\mathrm{TN}-\mathrm{C})$ levels in Kawasaki disease (KD) patients $(n=68)$ and healthy controls $(n=23)$. Serum levels were high on admission, but significantly decreased during the convalescent stage after intravenous immunoglobulin therapy in the KD patients.

predict IVIG resistance that could lead to the development of CAL. ${ }^{9-13}$ Because the accuracy of these systems has not been high in other countries, ${ }^{14}$ and they are cumbersome, a novel simple biomarker to predict the risk of CAL is required.

Tenascin-C (TN-C) is an extracellular matrix glycoprotein that is sparse in normal tissue, but upregulated at sites of tissue injury and inflammation. ${ }^{15-17}$ It has diverse functions in the regulation of cell behavior and tissue remodeling in many developmental and pathological processes. ${ }^{18-20}$ A growing number of studies have reported that serum $\mathrm{TN}-\mathrm{C}$ is elevated in various cardiovascular diseases and can be used as a biomarker for the diagnosis of disease activity, as well as a predictor of outcome in patients with aortic aneurysm/dissection, ${ }^{21,22} \mathrm{MI},{ }^{23}$ and dilated cardiomyopathy. ${ }^{15,16,24,25}$ The aim of this study was to determine whether serum TN-C could be used as a biomarker to predict the development of CAL and IVIG resistance in patients with acute KD.

\section{Methods}

\section{Subjects}

We conducted a multicenter retrospective study and enrolled $111 \mathrm{KD}$ patients and 23 age- and sex-matched healthy controls. Frozen serum samples from KD patients were collected from the following participating institutions: National Center for Global Health and Medicine, Toyama University, Mie University, and Kurume University. Frozen serum samples from healthy controls were collected from Nippon Medical School Musashikosugi Hospital. All KD patients fulfilled the criteria for the Diagnostic Guidelines for Kawasaki Disease. ${ }^{26}$ Each patient received $2 \mathrm{~g} / \mathrm{kg}$ of IVIG over $24 \mathrm{~h}$ and $30-50 \mathrm{mg} /$ $\mathrm{kg}$ /day of aspirin within 7 days of onset. The aspirin dosage was decreased to $5 \mathrm{mg} / \mathrm{kg} /$ day after patients became afebrile. We assessed the coronary arteries by $2 \mathrm{D}$ echocardiography before treatment and at least twice weekly thereafter. CAL were diagnosed if an examination showed an internal lumen diam-

\begin{tabular}{|c|c|c|c|}
\hline \multicolumn{4}{|c|}{$\begin{array}{l}\text { Table 1. Correlation Between Serum TN-C Level and Other } \\
\text { Laboratory Data }\end{array}$} \\
\hline & $\mathbf{n}$ & $\begin{array}{l}\text { Correlation } \\
\text { coefficient }\end{array}$ & $P$ value \\
\hline CRP & 104 & 0.369 & $<0.001$ \\
\hline WBC & 62 & - & 0.761 \\
\hline$\%$ Neutrophils & 92 & 0.287 & 0.005 \\
\hline Platelets & 98 & -0.229 & 0.023 \\
\hline Albumin & 58 & - & 0.165 \\
\hline T-bilirubin & 56 & - & 0.078 \\
\hline AST & 96 & - & 0.119 \\
\hline ALT & 68 & 0.451 & $<0.001$ \\
\hline Sodium & 93 & -0.232 & 0.025 \\
\hline
\end{tabular}

ALT, alanine aminotransferase; AST, aspartate aminotransferase; CRP, C-reactive protein; TN-C, tenascin-C; WBC, white blood cells.

eter $\geq 3 \mathrm{~mm}$ in children less than 5 years old and $\geq 4 \mathrm{~mm}$ in children 5 years or older; if the internal diameter of a given segment was at least 1.5-fold larger than that of an adjacent segment; or if the lumen appeared irregular. IVIG resistance was defined in cases of patients needing second-line therapy.

This study was approved by the Research Ethics Committee at each collaborative institution. Informed consent for the use of samples was given by participants or their parents/guardians.

\section{Measurement of Serum TN-C Levels}

Blood samples were obtained from $111 \mathrm{KD}$ patients on admission and from 68 of them while convalescing (after 25 days of illness and C-reactive protein (CRP) normalization; day 1 was defined as the first day of fever). The age- and sex-matched 23 healthy controls served the purpose of comparison. Blood samples were sent to the National Center for Global Health and 


\begin{tabular}{lccc}
\hline \multicolumn{4}{l}{ Table 2. Characteristics and Data Comparison of IVIG-Responder and IVIG-Resistant Groups of Patients } \\
With Kawasaki Disease & IVIG-responder group & IVIG-resistant group & P value \\
$\mathbf{n}$ & 89 & 22 & \\
Age, months & $24[2-84]$ & $21[4-72]$ & 0.742 \\
Male, $\mathbf{n}(\%)$ & $48(53.9)$ & $10(45.5)$ & 0.476 \\
Laboratory data before IVIG & & & \\
TN-C, $\mathrm{ng} / \mathrm{ml}$ & $69.6[28.8-266.0](n=89)$ & $114.0[35.3-653.4](n=22)$ & 0.003 \\
WBC, $\times 10^{3} / \mu \mathrm{I}$ & $13.7[6.9-28.0](n=52)$ & $11.6[6.1-16.9](n=10)$ & 0.053 \\
Neutrophils, \% & $70[25-93](n=77)$ & $78[38-87](n=15)$ & 0.269 \\
Platelets, $\times 10^{4} / \mathrm{ml}$ & $33.0[18.9-83.1](n=83)$ & $26.9[20.7-57.6](n=15)$ & 0.051 \\
CRP, mg/dl & $8.6[1.1-30.7](n=86)$ & $10.5[3.0-18.7](n=18)$ & 0.036 \\
Albumin, g/dl & $3.6[2.3-4.9](n=49)$ & $3.8[3.1-4.1](n=9)$ & 0.846 \\
T-bilirubin, mg/dl & $0.5[0.3-2.4](n=47)$ & $0.7[0.5-4.5](n=9)$ & 0.034 \\
AST, IU/L & $36[16-801](n=81)$ & $62[28-1,441](n=15)$ & 0.023 \\
ALT, IU/L & $35[6-272](n=52)$ & $80[7-764](n=10)$ & 0.206 \\
Sodium, mEq/L & $135[125-141](n=79)$ & $134[130-139](n=14)$ & 0.332 \\
\hline
\end{tabular}

Data are shown as median [range]. IVIG, intravenous immunoglobulin. Other abbreviations as in Table 1.

\begin{tabular}{|c|c|c|c|}
\hline & CAL(-) group & CAL(+) group & $P$ value \\
\hline $\mathbf{n}$ & 103 & 8 & \\
\hline Age, months & $24[2-84]$ & 20 [4-55] & 0.315 \\
\hline Male, n (\%) & $54(52.4)$ & $4(50.0)$ & 0.590 \\
\hline IVIG resistance, n (\%) & $17(16.5)$ & $5(62.5)$ & 0.007 \\
\hline \multicolumn{4}{|c|}{ Laboratory data before IVIG } \\
\hline $\mathrm{TN}-\mathrm{C}, \mathrm{ng} / \mathrm{ml}$ & $70.3[28.8-266.0](n=103)$ & $139.3[55.5-653.4](n=8)$ & 0.010 \\
\hline WBC, $\times 10^{3} / \mu \mathrm{l}$ & $12.7[6.1-28.0](n=58)$ & $9.8[6.9-16.7](n=4)$ & 0.295 \\
\hline Neutrophils, \% & 70 [25-93] (n=87) & $78[46-91](n=5)$ & 0.297 \\
\hline Platelets, $\times 10^{4} / \mathrm{ml}$ & $33.0[18.9-83.1](n=92)$ & $26.8[20.7-35.0](n=6)$ & 0.032 \\
\hline $\mathrm{CRP}, \mathrm{mg} / \mathrm{dl}$ & $8.7[1.1-30.7](n=97)$ & $10.7[8.3-17.5](n=7)$ & 0.064 \\
\hline Albumin, g/dl & $3.7[2.3-4.9](n=54)$ & $3.4[3.2-3.8](n=4)$ & 0.322 \\
\hline T-bilirubin, mg/dl & $0.6[0.3-4.5](n=53)$ & $1.6[0.6-2.0](n=3)$ & 0.114 \\
\hline AST, IU/L & $38[16-801](n=90)$ & $44[29-1,441](n=6)$ & 0.586 \\
\hline$A L T, I U / L$ & $34[6-535](n=58)$ & $249[56-764](n=4)$ & 0.008 \\
\hline Sodium, mEq/L & $135[125-141](n=88)$ & $134[129-136](n=5)$ & 0.189 \\
\hline
\end{tabular}

Data are shown as median [range]. CAL, coronary artery lesions. Other abbreviations as in Tables 1,2.

Medicine where serum TN-C was measured by enzyme-linked immunosorbent assay using the Human TN-C Large (FN 1llC) Assay Kit (Immuno-Biological Laboratories Co, Gunma, Japan). Medical, demographic, and laboratory data on admission were collected in all cases.

\section{Statistical Analysis}

All analyses were performed with SPSS software version 20 (SPSS Japan, Tokyo, Japan) and R ver. 3.1.0. Data are presented as median with the range for continuous variables, or as a percentage of the patients in a given categorical variable. A series of group comparisons were conducted using the t-test for numerical data of normal distribution, the Mann-Whitney $\mathrm{U}$ test for data that did not have normal distribution, and the Fisher exact and chi-square tests for categorical data. Comparisons of TN-C levels between admission and convalescence were performed with the Wilcoxon's signed rank test. Correlations between TN-C levels and other laboratory data were determined by Spearman's correlation coefficients. To compare the power of predicting IVIG resistance based on serum TN-C and Kobayashi score, receiver-operating characteristic curves were plotted and the areas under the curves (AUC) were calculated. We compared the predictive accuracy of the 2 models by DeLong test. All P values were 2-tailed; $\mathrm{P}<0.05$ was considered statistically significant.

\section{Results}

\section{Serum TN-C Levels in the Acute Phase of KD}

The change in TN-C levels between admission and convalescence was evaluated for 68 of 111 patients (Figure 1). Their $\mathrm{TN}-\mathrm{C}$ levels on admission were significantly higher than those of the healthy controls $(\mathrm{P}<0.001)$ and significantly decreased during convalescence after IVIG administration $(\mathrm{P}<0.001)$. $\mathrm{TN}-\mathrm{C}$ levels correlated positively with both $\mathrm{CRP}(\mathrm{P}<0.001)$ and the percentage of neutrophils $(\mathrm{P}=0.005)$, and negatively 
with platelet count $(\mathrm{P}=0.023)$; however, the correlation coefficients were not high (Table 1). We also compared TN-C levels with other laboratory parameters involved in risk scoring for KD. ${ }^{10,11,13} \mathrm{TN}-\mathrm{C}$ levels correlated positively with alanine aminotransferase $(\mathrm{ALT} ; \mathrm{P}<0.001)$ and negatively with sodium $(\mathrm{P}=0.025)$ levels. There was no correlation with white blood cell count, or total bilirubin, albumin, and aspartate aminotransferase (AST) levels.

\section{Serum TN-C Levels in IVIG-Responder and IVIG-Resistant Patients}

We compared the TN-C levels on admission of IVIG-responders $(n=89)$ with those of IVIG-resistant patients $(n=22)$. Serum TN-C levels were significantly higher in the IVIG-resistant patients than in the IVIG-responders $(\mathrm{P}=0.003$; Table 2). Significant differences in $\mathrm{CRP}(\mathrm{P}=0.036)$, total bilirubin ( $\mathrm{P}=0.034)$, and AST $(\mathrm{P}=0.023)$ were also found between the 2 groups.

\section{Comparison of Predicting IVIG Resistance by TN-C and Kobayashi Score}

IVIG resistance were predicted by receiver-operating characteristics curve analysis of TN-C levels in 83 cases comparing with the Kobayashi score. ${ }^{11}$ For predicting IVIG resistance, a TN-C cut-off value of $95.2 \mathrm{ng} / \mathrm{ml}$ yielded a sensitivity of $58 \%$, specificity of $78 \%$, a positive predictive value of $30 \%$, and a negative predictive value of $92 \%$. We also compared these 2 models and the percentage of IVIG-resistant cases in the highrisk group (Kobayashi score $>5$ points, $n=18$ ) were significantly higher than that of the low risk group (Kobayashi score $<5$ points, $\mathrm{n}=65)(9.1 \%$ vs. $33.3 \%$, respectively, $\mathrm{P}=0.019)$. The AUC of TN-C was comparable to that of the Kobayashi score (AUC 0.607 vs. 0.667, respectively; $\mathrm{P}=0.607$ ).

\section{Serum TN-C Levels in Patients With and Without CAL}

We compared the laboratory data of patients with CAL [CAL(+) group, $n=8$ ] and without [CAL(-) group, $n=103$ ]. TN-C levels in the CAL(+) group were significantly higher than in the CAL $(-)$ group $(\mathrm{P}=0.01$; Table 3$)$. Significant differences between the CAL $(+)$ and CAL $(-)$ groups were also seen in platelet counts $(\mathrm{P}=0.032)$ and ALT levels $(\mathrm{P}=0.008)$. Moreover, the rate of IVIG resistance was significantly higher in the CAL $(+)$ group than in the CAL $(-)$ group $(\mathrm{P}=0.007)$. No significant differences in CRP, total bilirubin and AST levels were found between the 2 groups. For predicting CAL formation by TN-C level on admission, a TN-C cut-off value of $113.3 \mathrm{ng} / \mathrm{ml}$ yielded a sensitivity of $63 \%$, specificity of $84 \%$, a positive predictive value of $23 \%$, and a negative predictive value of $97 \%$ with an AUC of 0.77 (95\% confidence interval $0.59-0.96, \mathrm{P}=0.01)$. Coronary angiography of a representative patient with high serum TN-C on admission and who eventually developed giant coronary aneurysm is shown in Figure 2.

\section{Discussion}

The results of this study indicated that the serum TN-C level might be a useful biomarker to predict the risk of developing CAL and IVIG resistance in the acute phase of KD. The accuracy of the prediction of IVIG resistance was comparable to that of the Kobayashi score, ${ }^{11}$ which is the most common risk scoring technique currently used. TN-C levels on admission were significantly higher in patients who later developed CAL than in patients who did not, and were significantly higher in IVIG-resistant patients than in IVIG-responders. Furthermore, serum TN-C levels on admission predicted the development of CAL and IVIG resistance with high accuracy. Recent

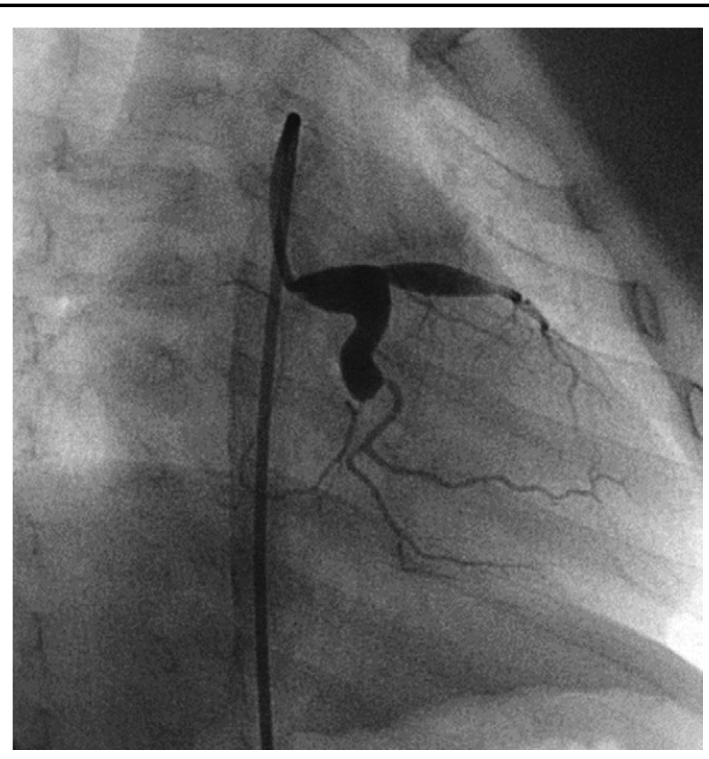

Figure 2. Coronary angiogram from a representative case, a 4-month-old boy, with a coronary artery lesion. Laboratory data showed increased serum levels of tenascin-C $(371 \mathrm{ng} / \mathrm{ml})$ and C-reactive protein $(17.5 \mathrm{mg} / \mathrm{dl})$. The patient was resistant to the initial course of intravenous immunoglobulin infusion and was febrile for 19 days.

advances in therapeutic strategies have provided additional treatment options, such as IVIG plus prednisolone, ${ }^{12}$ for patients at high risk of CAL; therefore, risk stratification of KD patients is a critical step. Several parameters, including the duration of fever, ${ }^{27-29}$ and the levels of vascular endothelial growth factor, ${ }^{30,31}$ B-type natriuretic peptide, ${ }^{32}$ serum albumin, ${ }^{33}$ serum sodium, ${ }^{34} \mathrm{CRP},{ }^{35}$ platelet-neutrophil aggregates, ${ }^{36}$ and inflammatory cytokines, including tumor necrosis factor- $\alpha$ and interleukin- $6,{ }^{35,37}$ are reported to predict the development of CAL. To improve the diagnostic accuracy for predicting IVIG resistance and CAL formation in KD patients, several clinical risk scoring systems have been developed using a combination of multiple patient profiles and laboratory parameters. ${ }^{10,11,13}$ The Kobayashi score ${ }^{11}$ in particular is often used in Japan to predict IVIG resistance. A recent study reported that the addition of prednisolone to initial IVIG treatment reduces the incidence of CAL in high-risk KD patients according to the Kobayashi score. ${ }^{12}$ However, a recent North American cohort generated controversy regarding the use of risk scores. ${ }^{14}$ Therefore, a novel and simple biomarker for risk stratification is necessary. In the present study, we have shown that the accuracy of predicting IVIG resistance via serum TN-C levels was comparable to that of the Kobayashi score, suggesting that serum $\mathrm{TN}-\mathrm{C}$ alone could be a biomarker to identify high-risk patients.

$\mathrm{TN}-\mathrm{C}$ could be a marker of inflammatory activity in $\mathrm{KD}$, because it is generally upregulated in inflammatory lesions and regulates inflammatory cell responses. ${ }^{17,38,39}$ Recently, elevated serum levels of $\mathrm{TN}-\mathrm{C}$ were reported to reflect local expression and are used as biomarkers for disease activity in pediatric patients with various inflammatory diseases, ${ }^{40-42}$ as well as in adults. ${ }^{15,16}$ In this study, we found that the serum TN-C levels of KD patients were elevated in the acute stage and the levels correlated with known inflammatory markers, such as percentage of neutrophils and CRP level, although the correlation coefficients were not high. In a mouse KD model, vascular 
lesions expressed TN-C, and expression correlated with the severity of inflammation. ${ }^{43}$ Therefore, serum TN-C levels in KD patients could reflect inflammatory activity in CAL.

$\mathrm{TN}-\mathrm{C}$ could be involved in the process of CAL formation and/or vascular remodeling in $\mathrm{KD}$. Analyses of several disease models have shown that the major sources of TN-C in vascular disease are medial smooth muscle cells and fibroblasts, especially myofibroblasts. ${ }^{15,16}$ Various proinflammatory cytokines and growth factors, in addition to mechanical stress, upregulate TN-C expression. Transforming growth factor- $\beta$, one of the key modulators of $\mathrm{KD}$ arteritis, ${ }^{44}$ is also known to induce $\mathrm{TN}-\mathrm{C}$ expression. TN-C acts as an autocrine/paracrine factor on smooth muscle cells, fibroblasts, and macrophages. ${ }^{16,38,45}$ For example, in a mouse model of aortic aneurysm/dissection, $\mathrm{TN}-\mathrm{C}$ is produced by vascular smooth muscle cells under strong humoral and mechanical stress, and protects the vascular wall by modulating inflammatory and fibrotic responses during pathological tissue remodeling. ${ }^{46}$ Although the exact roles of $\mathrm{TN}-\mathrm{C}$ in the cascade leading to CAL formation have yet to be elucidated, TN-C could be a novel marker of not only inflammation but also pathological tissue remodeling.

\section{Study Limitations}

First, the sample size might not be large enough to determine CAL and IVIG-resistance predictors. However, the frequency of IVIG resistance $(20 / 111,19.8 \%)$ was comparable to data from the National Registry, ${ }^{5}$ and reflected the general features of patients with KD. Second, the retrospective nature of this study prevented us from collecting complete data sets and precluded the use of multivariate logistic regression analysis to identify laboratory data predictive of IVIG resistance and increased risk of CAL. The frequency of CAL (8/111, 7.2\%) was somewhat higher than in the National Registry data, ${ }^{5}$ perhaps because our samples were obtained from severe KD cases admitted to collaborative tertiary care institutions. A larger scale prospective study is therefore needed.

In conclusion, the serum level of TN-C may be a promising new biomarker for predicting the risk of CAL and IVIG resistance in patients during the acute phase of KD. Early identification of IVIG resistance could help to prevent CAL through the addition of other antiinflammatory medicines to initial IVIG therapy.

\section{Acknowledgments}

We thank Mayumi Iwasaki and Chihiro Eguchi for measuring the serum levels of TN-C, and Kiyoshi Matsuoka, MSc for the statistical analyses. T.Y. receives royalties on $\mathrm{TN}-\mathrm{C}$ antibodies from Immuno-Biological Laboratories Co, Japan. Part of this study was presented at The Association for European Pediatric and Congenital Cardiology (AEPC 2013).

\section{Funding}

This work was supported by grants from the National Center for Global Health and Medicine (23D114), the Japanese Therapeutic Study Group for Kawasaki Disease (JSGK 2013) to Y.O., and grants for intractable disease from the Ministry of Health, Labour and Welfare of Japan (201128212, 201324121, 20145052) and a grant for Kawasaki Disease Research from Japan Blood Products Organization to K.I.-Y.

\section{References}

1. Burns JC, Glode MP. Kawasaki syndrome. Lancet 2004; 364: 533 544.

2. Furusho K, Kamiya T, Nakano H, Kiyosawa N, Shinomiya K, Hayashidera T, et al. High-dose intravenous gammaglobulin for Kawasaki disease. Lancet 1984; 2: 1055-1058.

3. Newburger JW, Takahashi M, Beiser AS, Burns JC, Bastian J, Chung KJ, et al. A single intravenous infusion of gamma globulin as compared with four infusions in the treatment of acute Kawasaki syndrome. N Engl J Med 1991; 324: 1633-1639.
4. Newburger JW, Takahashi M, Burns JC, Beiser AS, Chung KJ, Duffy CE, et al. The treatment of Kawasaki syndrome with intravenous gamma globulin. N Engl J Med 1986; 315: 341-347.

5. Makino N, Nakamura Y, Yashiro M, Ae R, Tsuboi S, Aoyama Y, et al. Descriptive epidemiology of Kawasaki disease in Japan, 20112012: From the results of the 22nd nationwide survey. J Epidemiol 2015; 25: 239-245.

6. Burns JC, Capparelli EV, Brown JA, Newburger JW, Glode MP. Intravenous gamma-globulin treatment and retreatment in Kawasaki disease: US/Canadian Kawasaki Syndrome Study Group. Pediatr Infect Dis J 1998; 17: 1144-1148.

7. Durongpisitkul K, Soongswang J, Laohaprasitiporn D, Nana A, Prachuabmoh C, Kangkagate C. Immunoglobulin failure and retreatment in Kawasaki disease. Pediatr Cardiol 2003; 24: 145-148.

8. Uehara R, Belay ED, Maddox RA, Holman RC, Nakamura Y, Yashiro M, et al. Analysis of potential risk factors associated with nonresponse to initial intravenous immunoglobulin treatment among Kawasaki disease patients in Japan. Pediatr Infect Dis J 2008; 27: $155-160$.

9. JCS Joint Working Group. Guidelines for diagnosis and management of cardiovascular sequelae in Kawasaki disease (JCS 2013): Digest version. Circ J 2014; 78: 2521 -2562.

10. Egami K, Muta H, Ishii M, Suda K, Sugahara Y, Iemura M, et al. Prediction of resistance to intravenous immunoglobulin treatment in patients with Kawasaki disease. J Pediatr 2006; 149: 237-240.

11. Kobayashi T, Inoue Y, Takeuchi K, Okada Y, Tamura K, Tomomasa $\mathrm{T}$, et al. Prediction of intravenous immunoglobulin unresponsiveness in patients with Kawasaki disease. Circulation 2006; 113: 26062612.

12. Kobayashi T, Saji T, Otani T, Takeuchi K, Nakamura T, Arakawa $\mathrm{H}$, et al. Efficacy of immunoglobulin plus prednisolone for prevention of coronary artery abnormalities in severe Kawasaki disease (RAISE study): A randomised, open-label, blinded-endpoints trial. Lancet 2012; 379: 1613-1620.

13. Sano T, Kurotobi S, Matsuzaki K, Yamamoto T, Maki I, Miki K, et al. Prediction of non-responsiveness to standard high-dose gammaglobulin therapy in patients with acute Kawasaki disease before starting initial treatment. Eur J Pediatr 2007; 166: 131-137.

14. Sleeper LA, Minich LL, McCrindle BM, Li JS, Mason W, Colan SD, et al. Evaluation of Kawasaki disease risk-scoring systems for intravenous immunoglobulin resistance. J Pediatr 2011; 158: 831-835. e833.

15. Imanaka-Yoshida $\mathrm{K}$. Tenascin- $\mathrm{C}$ in cardiovascular tissue remodeling: From development to inflammation and repair. Circ J 2012; 76: $2513-2520$.

16. Imanaka-Yoshida K, Yoshida T, Miyagawa-Tomita S. Tenascin-C in development and disease of blood vessels. Anat Rec (Hoboken) 2014; 297: 1747-1757.

17. Midwood KS, Hussenet T, Langlois B, Orend G. Advances in tenascin-C biology. Cell Mol Life Sci 2011; 68: 3175-3199.

18. Chiquet-Ehrismann R, Orend G, Chiquet M, Tucker RP, Midwood KS. Tenascins in stem cell niches. Matrix Biol 2014; 37: 112-123.

19. Giblin SP, Midwood KS. Tenascin-C: Form versus function. Cell Adh Migr 2015; 9: 48-82.

20. Spenle C, Saupe F, Midwood K, Burckel H, Noel G, Orend G. Tenascin-C: Exploitation and collateral damage in cancer management. Cell Adh Migr 2015; 9: 141-153.

21. Nozato T, Sato A, Hikita H, Takahashi A, Imanaka-Yoshida K, Yoshida $\mathrm{T}$, et al. Impact of serum tenascin- $\mathrm{C}$ on the aortic healing process during the chronic stage of type $\mathrm{B}$ acute aortic dissection. Int J Cardiol 2015; 191: 97-99.

22. Nozato T, Sato A, Hirose S, Hikita H, Takahashi A, Endo H, et al. Preliminary study of serum tenascin-C levels as a diagnostic or prognostic biomarker of type B acute aortic dissection. Int J Cardiol 2013; 168: 4267-4269.

23. Sato A, Aonuma K, Imanaka-Yoshida K, Yoshida T, Isobe M, Kawase D, et al. Serum tenascin-C might be a novel predictor of left ventricular remodeling and prognosis after acute myocardial infarction. J Am Coll Cardiol 2006; 47: 2319-2325.

24. Franz M, Jung C, Lauten A, Figulla HR, Berndt A. Tenascin-C in cardiovascular remodeling: Potential impact for diagnosis, prognosis estimation and targeted therapy. Cell Adh Migr 2015; 9: 90-95.

25. Golledge J, Clancy P, Maguire J, Lincz L, Koblar S. The role of tenascin C in cardiovascular disease. Cardiovasc Res 2011; 92: $19-28$.

26. Ayusawa M, Sonobe T, Uemura S, Ogawa S, Nakamura Y, Kiyosawa N, et al. Revision of diagnostic guidelines for Kawasaki disease (the 5th revised edition). Pediatr Int 2005; 47: 232-234.

27. Beiser AS, Takahashi M, Baker AL, Sundel RP, Newburger JW. A predictive instrument for coronary artery aneurysms in Kawasaki 
disease: US Multicenter Kawasaki Disease Study Group. Am J Cardiol 1998; 81: 1116-1120.

28. Ruan Y, Ye B, Zhao X. Clinical characteristics of Kawasaki syndrome and the risk factors for coronary artery lesions in China. Pediatr Infect Dis J 2013; 32: e397-e402, doi:10.1097/INF. 0b013e31829dd45e.

29. Song D, Yeo Y, Ha K, Jang G, Lee J, Lee K, et al. Risk factors for Kawasaki disease-associated coronary abnormalities differ depending on age. Eur J Pediatr 2009; 168: 1315-1321.

30. Ohno T, Yuge T, Kariyazono H, Igarashi H, Joh-o K, Kinugawa N, et al. Serum hepatocyte growth factor combined with vascular endothelial growth factor as a predictive indicator for the occurrence of coronary artery lesions in Kawasaki disease. Eur J Pediatr 2002; 161: $105-111$.

31. Terai M, Honda T, Yasukawa K, Higashi K, Hamada H, Kohno Y. Prognostic impact of vascular leakage in acute Kawasaki disease. Circulation 2003; 108: 325-330.

32. Kaneko K, Yoshimura K, Ohashi A, Kimata T, Shimo T, Tsuji S. Prediction of the risk of coronary arterial lesions in Kawasaki disease by brain natriuretic peptide. Pediatr Cardiol 2011; 32: 1106-1109.

33. Printz BF, Sleeper LA, Newburger JW, Minich LL, Bradley T, Cohen MS, et al. Noncoronary cardiac abnormalities are associated with coronary artery dilation and with laboratory inflammatory markers in acute Kawasaki disease. J Am Coll Cardiol 2011; 57: $86-92$.

34. Nakamura Y, Yashiro M, Uehara R, Watanabe M, Tajimi M, Oki I, et al. Use of laboratory data to identify risk factors of giant coronary aneurysms due to Kawasaki disease. Pediatr Int 2004; 46: 33-38.

35. Koyanagi H, Yanagawa H, Nakamura Y, Yashiro M. Serum C-reactive protein levels in patients with Kawasaki disease: From the results of nation-wide surveys of Kawasaki disease in Japan. Acta Paediatr 1997; 86: 613-619.

36. Ueno K, Nomura Y, Morita Y, Eguchi T, Masuda K, Kawano Y. Circulating platelet-neutrophil aggregates play a significant role in Kawasaki disease. Circ J 2015; 79: 1349-1356.
37. Lin CY, Lin CC, Hwang B, Chiang BN. Cytokines predict coronary aneurysm formation in Kawasaki disease patients. Eur J Pediatr 1993; 152: 309-312.

38. Shimojo N, Hashizume R, Kanayama K, Hara M, Suzuki Y, Nishioka $T$, et al. Tenascin-C may accelerate cardiac fibrosis by activating macrophages via the integrin alphaVbeta3/nuclear factorkappaB/interleukin-6 axis. Hypertension 2015; 66: 757-766.

39. Udalova IA, Ruhmann M, Thomson SJ, Midwood KS. Expression and immune function of tenascin-C. Crit Rev Immunol 2011; 31: $115-145$.

40. Karatas Z, Baysal T, Alp H, Toker A. Serum tenascin-C: A novel biomarker for diagnosis and predicting prognosis of rheumatic carditis? J Trop Pediatr 2013; 59: 476-482.

41. Kotby AA, Abdel Aziz MM, El Guindy WM, Moneer AN. Can serum tenascin-C be used as a marker of inflammation in patients with dilated cardiomyopathy? Int J Pediatr 2013; 2013: 608563.

42. Shukla A, Gaur P, Aggarwal A. Tenascin-C Levels, A toll-like receptor 4 ligand, in enthesitis-related arthritis category of juvenile idiopathic arthritis: A cross-sectional and longitudinal study. J Rheumatol 2015; 42: 891-896.

43. Yoshikane Y, Koga M, Imanaka-Yoshida K, Cho T, Yamamoto Y, Yoshida T, et al. JNK is critical for the development of Candida albicans-induced vascular lesions in a mouse model of Kawasaki Disease. Cardiovasc Pathol 2015; 24: 33-40.

44. Shimizu C, Oharaseki T, Takahashi K, Kottek A, Franco A, Burns JC. The role of TGF-beta and myofibroblasts in the arteritis of Kawasaki disease. Hum Pathol 2013; 44: 189-198.

45. Kanayama M, Kurotaki D, Morimoto J, Asano T, Matsui Y, Nakayama Y, et al. Alpha9 integrin and its ligands constitute critical joint microenvironments for development of autoimmune arthritis. $J$ Immunol 2009; 182: 8015-8025.

46. Kimura T, Shiraishi K, Furusho A, Ito S, Hirakata S, Nishida N, et al. Tenascin C protects aorta from acute dissection in mice. Sci Rep 2014; 4: 4051 